Особое внимание необходимо уделять студентам первых и вторых курсов. В этот период начального освоения будущей профессиональной деятельности очень важно поддержать у них желание продуктивно заниматься интеллектуальной деятельностью. Подготовка конкурсной работы для них - это интересная учебнопознавательная деятельность под руководством преподавателя, выступающего в роли научного руководителя или координатора. Управление деятельностью студентов при выполнении учебного проекта требует от преподавателя педагогических умений творчески использовать метод проектов [4] в своей профессиональной деятельности.

Интеграция в определенную систему различных видов умственной деятельности создает условия для более эффективной реализации концепции личностно-ориентированного подхода к организации учебного процесса в вузе. Подготовка конкурсных работ вызывает яркие эмоциональные впечатления у студентов, активизирует их познавательный интерес к освоению нового информационного и коммуникационного пространства.

Диалогическое общение студентов с преподавателем в процессе выполнения интеллектуального учебного проекта способствует активизации мыслительной деятельности субъектов образовательного процесса. Целенаправленное применение активных и интерактивных методов обучения в единстве обеспечивает более успешное развитие культуры мышления студентов вуза при выполнении ими различных дидактических заданий, учебных и творческих проектов.

$$
* * *
$$

1. Куликова О.В. Культура мышления и критерии развития ее компонентов в учебном процессе вуза: монография [Текст] / О.В. Куликова. - Екатеринбург: УрГУПС, 2010. - 114 с.

2. Кныш А.А., Куликова О.В. Моделирование проектной деятельности студентов при выполнении учебного проекта [Электронный ресурс] // А.А.Кныш, О.В.Куликова. Итоги научноисследовательской деятельности 2017: изобретения, методики, инновации: сборник научных трудов XXIX Международной научно-практической конференции. - М. : Издательство «Олимп», 2017. C.449-450.

3. Новиков А.М., Новиков Д.А. Образовательный проект (методология образовательной деятельности) [Текст] / А.М. Новиков, Д.А. Новиков. - М. : Эгвес, $-2004 .-120$ с.

4. Новые педагогические и информационные технологии в системе образования [Текст] / Е.С. Полат, М.Ю. Бухаркина, М.В. Моисеева, А.Е. Петров; под ред. Е.С. Полат. - 3-е изд., испр. и доп. - М. : Академия, 2008. $-272 \mathrm{c}$.

\title{
Фасхутдинов Р.T. \\ Осмысленность жизни и мотивационно-смысловые образования в процессе адаптации студентов в вузе
}

Ярославский государственный университет им. П.Г. Демидова (ЯрГУ)

(Россия, Ярославль)

doi 10.18411/spc-12-01-2018-05

idsp 000001:spc-12-01-2018-05

Проблема адаптации достаточно длительное время находится в фокусе внимания исследователей разных направлений отечественной и зарубежной психологии . Одним из перспективных, по мнению В . В. Знакова, является экзистенциальный подход к проблемам адаптации человека в обществе (Знаков, 2016). В контексте данного подхода осуществляется определение личности через мораль: в чем человек видит смысл своего существования . Адаптация студентов проблема емкая , ибо содержание процесса адаптации включает в себя множество стадий и механизмов, что подчеркивает ее полиструктурность, полифункциональность и позволяет рассматривать вопрос на разных уровнях : начиная с феноменологии вопроса , заканчивая детальным разбором механизмов, способов и стратегий поведения . В литературе можно встретить разную классификацию по видам адаптации и уровням ее анализа (Кашапов, 2015). При этом 
подчеркивается, что личность является носителем содержания внутреннего мира человека, которое субъект реализует вконкретных жизненных условиях и обстоятельствах (Сергиенко и др., 2009; Сергиенко, Виленская, 2010).

Эффективность процесса социально-психологической адаптации во многом зависит от осмысленности жизни человека и его мотивационно -смысловых образований. При этом особую роль играет жизненный смысл как объективная характеристика места и роли объектов , явлений и событий действительности и действий субъекта в контексте его жизни. Жизненный смысл объективен, подчеркивает Д. А. Леонтьев, ибо независит от его осознания, при этом он индивидуален, неповторим. Это не психологическое, а скорее метафизическое понятие (Леонтьев, 2006).

Исследование мотивационной направленности студентов вуза определяется необходимостью обновления не только содержания , но и технологий образования в высшей школе в условиях введения нового федерального государственного образовательного стандарта.

Цель: изучить особенности влияния смысложизненных ориентаций и мотивационно-смысловых образований на процесс социально - -психологической адаптации студентов в вузе.

В качестве гипотез исследования мы выдвинули предположения о том , что на уровень социально -психологической адаптац ии будут влиять : наличие в жизни испытуемого целей будущего, которые придают жизни осмысленность; осмысленность жизни в целом; мотивационная направленность личности.

Методики:тест смысложизненных ориентаций «СЖО» (Д. А. Леонтьев), методика диагностики социально-психологической адаптации (К. Роджеса и Р . Даймонда), опросник «Мотивация к избеганию неудач » (Т. Элерса), методы статистической обработки.

При планировании структуры эмпирического исследования использовалась однофакторная схема планирования. Межгрупповой фактор - принадлежность испытуемых к группам : a) «Адаптированные»; б) «Дезадаптированные». Принадлежность испытуемых к од - ной из двух групп оценивалась по методике диагностики социально-психологической адаптации (К. Роджерса и Р. Даймонда).

Процедура исследования. Эмпирическое исследование мы начали с входного тестирования. По результатам предварительного тестирования учащиеся были разделены на группы: «адаптированные» - «дезадаптированные».

Выборка. Исследование проводилось на базе Ярославского филиала Московского финансово-юридического университета (МФЮА). В качестве испытуемых приняли участие 74 студента-первокурсника специальности «таможенное дело » (39 девушек и 35 юношей) в возрасте от 17 до 22 лет.

Обработка данных и статистическийанализ результатов проводился в системе IBM SPSS 22.0. Использовались процедуры : описательных статистик ; корреляционного анализа по Пирсону ; однофакторный дисперсионный анализ (ANOVA); t-критерия Стьюдента для независимых выборок.

\section{Результаты и обсуждение}

1. Результаты дисперсионного анализа обнаружили статистически достоверный эффект фактора «Группа испытуемых » на показатели величины мотивационной направленности личности , изучаемой через конструкт мотивации избегания неудач $(\mathrm{F}(17,499)=125,185, \mathrm{p}=0,00)$. Показатели величины мотивационной направленности личности в группе «адаптированных» субъектов показало преимущество в сравнении с испытуемыми группы «дезадаптированных» субъектов, т. е. студентам, относящимся к группе «адаптированных» субъектов, в качестве мотивационной направленности присущамотивация избегания неудач · Студенты, 
которым свойственна мотивация избегания неудач концентрируются на возможных сложностях, стараются минимизировать потери в ситуации достижения своих целей. У них повышена тревожность из -за постоянных сомнений и неуверенности в своих силах решить проблемы и достичь успеха . Однако эта мотивационная стратегия заставляет работать больше , чем обычно , появление непредвиденных сложностей может значительно повлиять на эффективность их действий . мотивацией, направленной на избегание неудач , характерна малоинициативность , уклонение от заданий с высокой степенью ответственности , различные способы отказа, ухода от них. Помимо прочего , можно выделить свойственную подобным студентаммалую степень настойчивости в достижении цели, преимущественный выбор простых, нетрудоемких заданий , недооценивание своих возможностей и нестабильность самооценки при столкновении с неудачами. is토.

2. Результаты дисперсионного анализа также обнаружили статистически достоверный эффект фактора «Группа испытуемых» на показатели величины по шкале «цели в жизни» $(\mathrm{F}(60,282)=189,406,3 . \mathrm{p}=0,00)$. Показатели величины по шкале «цели в жизни» в группе «адаптированных» субъектов показало преимущество в сравнении с испытуемыми группы «дезадаптированных» субъектов, т.е. студенты, входящие в группу «адаптированных» субъектов, имеют больше целей в жизни , в сравнении со студентами, входящих в группу «дезадаптированных» субъектов. в группу «дезадаптированных» субъектов, зачастую не имеют представления о будущем, живут сегодняшним днем , не уделяя достаточно внимания процессу постановки и планирования целей . Отсутствие представлений о будуще м, его целей и смысла создает ситуацию нестабильности и, как результат - трудности, связанные, прежде всего, с усложнением в поиске ответа на проблемные вопросы, касающиеся

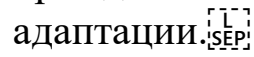

3. Результаты дисперсионного анализа также обнаружили статистически достоверный эффект фактора «Группа испытуемых» на показатели величины по шкале «осмысленность жизни» $(\mathrm{F}(11,479)=119,995, \mathrm{p}=0,00)$. Показатели величины по шкале«осмысленность жизни» в группе «адаптированных» субъектов показало преимущество в сравнении с испытуемыми группы «дезадаптированных» субъектов, т.е. студентам, относящимся к группе «адаптированных» субъектов, в большей степени характерна осмысленность жизни , в сравнении с группой «дезадаптированных» субъектов.

Анализ полученных результатов позволяет отметить, что в целом студенты первокурсники удовлетворены прожитой жизнью . Настоящую жизнь воспринимают интересной и эмоционально насыщенной . Студенты имеют определенные цели на будущую жизнь. Однакоони не совсем уверены, что способны контролировать свою жизнь, свободно принимать решения и воплощать их в жизнь . На уровень социально психологической адаптации действительно влияют наличие в жизни испытуемого целей будущего, общий показатель осмысленности жизни и мотивационная направленность личности. Таким образом, наши гипотезы исследования подтвердились.

\section{Выводы}

1. Установлены причинно -следственные связи между параметрами осмысленности жизни и социально -психологической адаптацией : чем выше осмысленность жизни, тем выше уровень развития социально-психологической адаптации.

2. Мотивация избегания неудач характерна для студентов, относящихся к группе «адаптированных» субъектов. "iL

3. Студенты с ориентацией на успех способны к быстрой мобилизации внутренних ресурсов при столкновении с неудачами , обладают адекватной оценкой 
своих возможностей , используют интеллектуальные ресурсы, незамедлительно

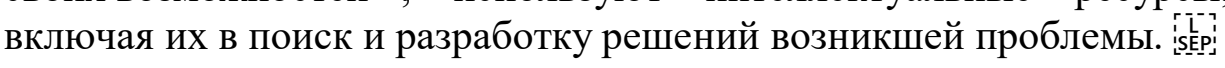

$$
* * *
$$

1. Знаков В.В. Психология понимания мира человека. М.: Изд-во «Институт Психологии РАН», 2016.

2. Кашапов А.С. Социально-психологическая адаптированность студентов: проблемы и решения: монография. Ярославль, ИПК «Индиго», 2015.

3. Леонтьев Д.А. К психологии поступка // Экзистенциальная традиция: философия, психология, психотерапия. Ростов н/Д., 2006. Вып. 2. С. 153-158.

4. Сергиенко Е.А., Лебедева Е.И., Прусакова О.А. Модель психического в онтогенезе человека. М.: Изд-во «Институт Психологии РАН», 2009.

5. Сергиенко Е.А., Виленская Г.А., Ковалева Ю.В. Контроль поведения как субъектная регуляция. М.: Изд-во «Институт Психологии РАН». 2010.

\section{Цзоу Лихуэй \\ Исследование развития способности к культурной эмпатии при аудиовизуальном обучении русскому языку в университете}

Хэйлунцзянский государственный технологический институт (КНР, Цзиси)

doi 10.18411/spc-12-01-2018-06

idsp 000001:spc-12-01-2018-06

\section{Аннотация}

Язык и культура тесно связаны. Обучение русскому языку - это изучение языка, что также неотделимо от изучения культуры. Культурная эмпатия является ключом к тому, чтобы сделать русский язык действительно эффективным, а также важной гарантией эффективного межкультурного общения. Развитие культурной эмпатии также является проблемой, о которой в последние годы обращают внимание преподаватели университетов России. Эта статья начинается с теории культурного сочувствия в межкультурной коммуникации и исследует, как развивать культурную эмпатиюу студентов в университете в русском аудиовизуальном обучении, понимая реальную ситуацию сочувственных способностей студентов.

\section{Abstract}

Language and culture are closely related. The teaching of Russian is the study of the language, which is also inseparable from the study of culture. Cultural empathy is the key to making the Russian language really effective, and also an important guarantee of effective intercultural communication. The development of cultural empathy is also a problem, which teachers of Russian universities have been paying attention to in recent years. This article starts with the theory of cultural sympathy in intercultural communication and explores how to develop cultural empathy among students at the university in Russian audiovisual learning, understanding the real situation of students' sympathetic abilities.

В университетах Китая, русское аудиовизуальное обучение, является профессиональным и обязательным. Основная практика методов обучения сочетается с преподаванием других курсов для достижения цели обучения, повышения уровня слуха,восприятия и речи. Слушание и разговорная подготовка занимают важное место в изучении русского языка. Независимо от точки зрения преподавания или языкового инструментализма или развивающейся тенденции преподавания иностранных языков, обучение «прослушиванию» и «разговором» является основными задачами преподавания иностранных языков. Слушание часто играет фундаментальную и решающую роль в умении говорить, например, слушать, говорить, читать, писать и 